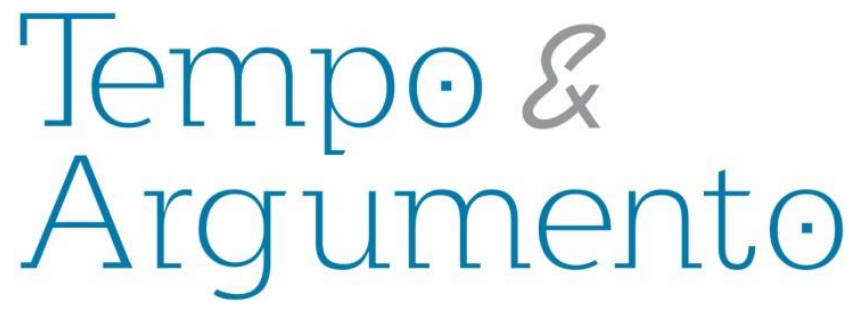

\title{
Narrativas sobre mulheres negras: diálogos entre a História e a Museologia
}

\section{Resenha da obra:}

SILVA, Joana Angélica Flores. Mulheres negras e museus de Salvador: Diálogos em branco e preto. Salvador: Edufba, 2017.

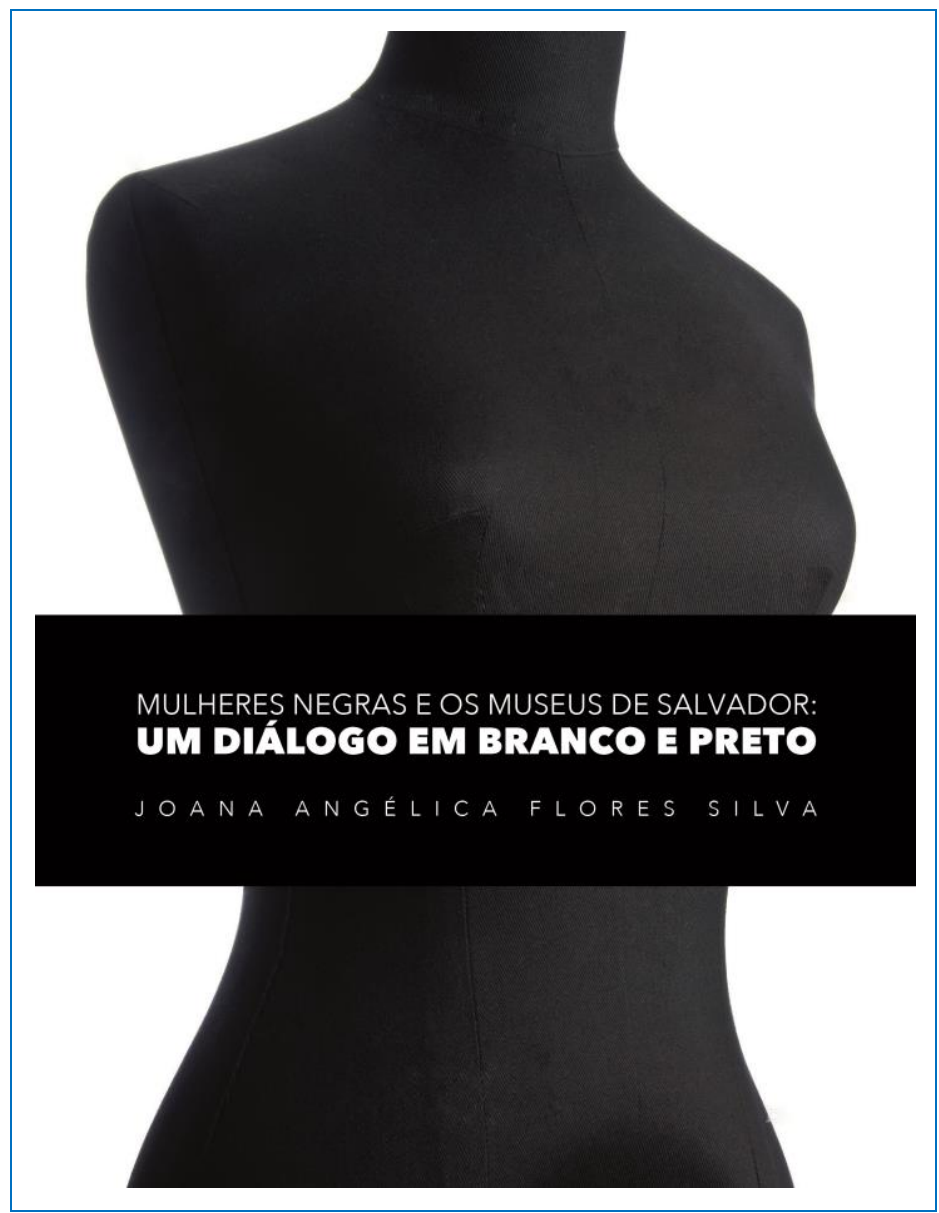

\section{Autora da resenha}

\section{Fernanda Lucas Santiago}

Mestranda em História na Universidade do Estado de Santa Catarina (UDESC).

Florianópólis - SC - Brasil flucasantiago@gmail.com

\section{Para citar esta resenha:}

SILVA, Joana Angélica Flores. Mulheres negras e museus de Salvador: Diálogos em branco e preto. Salvador: Edufba, 2017. Resenha de: SANTIAGO, Fernanda Lucas. Narrativas sobre mulheres negras: diálogos entre a História e a Museologia. Revista Tempo e Argumento, Florianópolis, v. 10, n. 25, p. 509 - 514. jul./set. 2018. 
Nós, historiadoras/es, partilhamos com nossas/os colegas museólogas/os alguns dilemas próprios do nosso ofício, como a responsabilidade com a narrativa que construímos, os desafios da análise crítica à fonte documental e o risco da fetichização e folclorização dos documentos. Para além disso, a função social de ambas as profissões, está intimamente ligada com a desconstrução de estereótipos e a necessidade constante de rever métodos e atualizar abordagens discursivas, entre outros aspectos. Desse modo, tanto na História como na Museologia, e em outras ciências humanas, a análise das fontes é o ponto-chave na construção da narrativa em que não se pode esperar que a fonte fale por si. Anterior à análise da fonte é necessário ter em vista o que pode ser considerado fonte. Quais sujeitos essa, ou aquela fonte nos permite acessar? Apesar dessas discussões não serem novidade na área da História, ainda determinados sujeitos ficam à margem das narrativas especialmente quanto à interseccionalidade de gênero, raça e classe. Qual o lugar destinado à mulher negra nas narrativas históricas? Qual o lugar destinado às mulheres negras nas exposições museológicas?

Nesse sentido, Joana Flores Silva critica a "romantização da escravidão" nos museus de Salvador e o "não lugar" da mulher negra nos museus e em nossa sociedade. Foram essas questões, que motivaram a Museóloga a aprofundar sua análise e escrever sua dissertação de Mestrado em Museologia (2015) pela UFBA. Essa resenha refere-se ao texto de sua dissertação, cujo lançamento em formato de livro deu-se no dia 21 de julho de 2017 no Solar Ferrão1, Pelourinho, Salvador - BA. A pesquisadora possui profunda experiência na área da Museologia, assumiu diversos cargos de gestão e coordenação de museus em instituições governamentais, sendo responsável por diversos projetos com a finalidade de criar políticas públicas para atender a demanda social com relação às questões de acessibilidade, identidade e pertencimento do público soteropolitano. Sua militância segue lado a lado com sua sólida trajetória profissional. Atualmente, é museóloga da Universidade Federal do Recôncavo da Bahia.

\footnotetext{
${ }^{1}$ Disponível em: <https://g1.globo.com/bahia/noticia/livro-mulheres-negras-e-museus-de-salvador-e-lancadono-solar-ferrao-nesta-sexta-feira.ghtml>. Acesso em: 30 abr. 2018.
} 
O lançamento do livro "Mulheres negras e museus de Salvador: Diálogo em Branco e Preto" é um marco na Museologia brasileira, pois inaugura² a discussão de gênero e raça, além de ser um ato político extremamente simbólico a presença de uma museóloga negra discutindo racismo; representatividade; o lugar da população negra na narrativa oficial; acessibilidade aos museus; no mesmo lugar em que, há pouco mais de um século, pessoas negras estavam sendo vendidos em praça pública.

A pesquisadora analisou sete museus de tipologia histórica de Salvador contidos no Guia Brasileiro de Museus, buscando entender como são representadas as mulheres em exposições de longa duração, e o tratamento diferenciado dado às representações de mulheres negras e mulheres brancas. Para entender a composição dos cenários dos museus analisados, a museóloga considerou duas etapas do projeto expográfico: a primeira refere-se à preservação dos objetos, ou seja, o que é valorizado como documento digno de preservação? O que compõe uma coleção? E a segunda etapa referese à exibição. O que merece ser exibido ao público? Quem são os sujeitos representados nos lugares de maior ou menor destaque dentro dos museus?

Como resultado da análise, a museóloga percebe que os acervos são pouco explorados e/ou distorcidos, no que tange a representação da mulher negra; há pouca ou ausência de referência sobre objetos que são atribuídos às mulheres negras. Caso parecido ocorre na História, quanto à invisibilidade das mulheres negras nas narrativas históricas. É necessário pensar qual a importância desse sujeito histórico (mulher negra) naquele contexto, e as experiências das mulheres negras na atualidade, e assim, questionar a intencionalidade de ligar o corpo negro ao passado de escravidão, promovendo seu silenciamento.

A museóloga explica que os recursos de luz e cor, conteúdo das legendas, a escolha dos objetos e espaços de maior ou menor destaque nos museus, evidenciam a intencionalidade expográfica de cristalizar hierarquias sociais. Assim como na narrativa histórica, escolhe-se apenas o que se deseja lembrar e o restante é esquecido, não há espaço para a pluralidade de experiências. A memória da mulher branca e pobre é

\footnotetext{
${ }^{2}$ Disponível em: $<$ https://dimusbahia.wordpress.com/2017/07/25/lancamento-do-livro-de-joana-floresmulheres-negras-e-museus-de-salvador-lota-o-museu-abelardo-rodrigues/>. Acesso em: 30 abr. 2018.
} 
apagada, assim como a memória de mulheres negras livres e com poder de influência são esquecidas. Cristalizar a imagem da mulher negra como escravizada impede-nos de perceber a história da mulher negra para além dessa imagem, invisibiliza suas ações enquanto sujeito histórico ativo na construção socioeconômica do país e sua atuação como líderes comunitárias, em clubes, coletivos e outros movimentos sociais. Segundo a museóloga, a memória da mulher branca da elite nos museus de Salvador é sustentada através da memória da mulher negra escravizada, ou seja, a memória de um grupo é reforçada pela subalternização da memória de um outro grupo .

Joana Silva faz um apelo no sentido de que as teorias e práticas museológicas devem ir além de pensar no acesso ao museu, mas devem repensar as formas de representar os sujeitos que não frequentam museus, por não se reconhecerem nos discursos ultrapassados exibidos nessas instituições. É necessário dar um tratamento digno aos objetos que pertenceram às mulheres negras e contextualizar os usos dos objetos, que são parte da história esquecida pela historiografia oficial. Trazer legendas com referências mais precisas sobre os objetos e sujeito que os possuíam, ou os utilizavam. Tornar visível a herança cultural desde tempos remotos dos grupos excluídos, para resgatar o sentimento de pertencimento e identidade racial e social dos sujeitos históricos no presente. A autora indica como possibilidade contrapor historiografia oficial com as produções artísticas que valorizam a mulher negra.

A pesquisadora apresenta alguns marcos de reflexões sobre a função social do museu que está na pauta da Museologia internacional dos últimos 40 anos: a Mesa Redonda de Santiago no Chile em 1972, segundo Silva (2017, p.51) “o desenvolvimento e o papel dos museus no mundo contemporâneo"; a Declaração de Caracas, de 1992, de acordo com Silva (2017, p. 51) "compreende os museus como um dos principais agentes de desenvolvimento integral”. O Código de ética do ICOM (Conselho Internacional de Museus) que assegura a autonomia dos museus no tratamento de suas coleções mas, atenta para o compromisso em tornar acessível e representativo para os diversos grupos sociais. Mesmo após esses avanços, a autora constata que a maioria dos museus de Salvador ainda não se alinharam a essas determinações internacionais. 
A museóloga também apresentou marcos nacionais de maior relevância para a renovação da museologia, como a Constituição de 1988, que instituiu o Plano Nacional de Cultura. As conquistas do movimento negro através das Políticas de Ações Afirmativas, como a criação da SEPPIR (Secretaria de Políticas de Promoção à Igualdade Racial) e SEPROMI (Secretaria de Promoção à Igualdade Racial), o Estatuto da Igualdade Racial. Esses marcos de Políticas Públicas sinalizam, de maneira geral, o respeito à diversidade cultural, a atualização da narrativa de maneira que promova a valorização dos sujeitos e grupos excluídos, resgatando o sentimento de pertença e identidade cultural.

A autora apresenta um breve histórico abordando a fundação de três instituições: o Instituto Histórico e Geográfico Brasileiro em 1838, o Museu Histórico Nacional do Rio de Janeiro em 1922 e o Instituto Feminino da Bahia fundado em 1923. Segundo a autora, essas três instituições foram responsáveis por construir os símbolos de identidade nacional, progresso, modernidade, o modelo de mulher burguesa e por cristalizar o continuísmo do espaço marginal destinado à população negra e indígena no estado da Bahia.

A narrativa oficial da História inseriu a mulher negra no papel de escravizada e da mesma forma operou o discurso Museológico durante anos. Tanto a historiografia quanto a museologia são beneficiadas quando as/os pesquisadoras/res consideram em suas abordagens o recorte racial, e suas interseccionalidades com gênero e classe. Faz-se urgente a difusão de trabalhos como de Silva (2017) para o combate ao racismo, machismo e sexismo. Esse trabalho de análise da museóloga deve servir de exemplo as/aos pesquisadoras/res brasileiros, assim como em todo mundo afro-diaspórico. Não se trata de tentar esconder o passado de escravidão mas, trata-se de evidenciar que a população afro-diaspórica tem uma história rica e plural em experiências, não sendo aceitável a reificação da imagem do escravizado. Silva (2017) traz nas últimas páginas de seu texto uma lista emblemática referenciando diversas mulheres negras que merecem ser lembradas por seu trabalho e atuação política, como Maria Beatriz Nascimento, Karol com K, Jovelina Pérola Negra, Olga de Alaketu, Tia Ciata, Djamila Ribeiro entre outras.

Entre as funções sociais do museu também podemos considerar a função didático-pedagógica, para que os museus possam servir aos propósitos da Lei 10.639/03, 
que instituiu a obrigatoriedade do Ensino de História e Cultura Africana e Afro-brasileira no Ensino Básico, desde que os objetos representados dialoguem com o público visitante numa perspectiva de desconstruir estereótipos; dessa forma, os museus podem ser aliados na construção de uma Educação Intercultural.

\section{Referências}

SILVA, Joana Angélica Flores. Mulheres negras e museus de Salvador: Diálogos em branco e preto. Salvador: Edufba, 2017.

Escritora Joana Flores lança livro ‘Mulheres Negras e Museus de Salvador’ no Solar Ferrão. G1 Bahia. Disponível em: <https://g1.globo.com/bahia/noticia/livro-mulheresnegras-e-museus-de-salvador-e-lancado-no-solar-ferrao-nesta-sexta-feira.ghtml> Acesso em: 30 abr. 2018.

Lançamento do livro de Joana Flores ‘Mulheres Negras e Museus de Salvador’ lota o Museu Abelardo Rodrigues. Dimus Bahia. Disponível em:

$<$ https://dimusbahia.wordpress.com/2017/07/25/lancamento-do-livro-de-joana-floresmulheres-negras-e-museus-de-salvador-lota-o-museu-abelardo-rodrigues/> Acesso em: 30 de abr. 2018. 